\section{$\mathbb{T}$ Periodica Polytechnica Civil Engineering}

\author{
62(2), pp. 533-538, 2018 \\ https://doi.org/10.3311/PPci.11295 \\ Creative Commons Attribution (i)
}

\title{
Numerical Investigation of Stress Distributions in Stope Backfills
}

\author{
Qingyang $\mathrm{Yu}^{1,2}$, Xiangli Chen ${ }^{1}$, Zhenxue Dai ${ }^{1,2,3}$, Lie Nei ${ }^{1}$, \\ Mohamad Reza Soltanian ${ }^{4,5}$
}

TECHNICAL NOTE

Received 22 July 2017; Revised 29 October 2017; Accepted 30 November 2017

\begin{abstract}
Stope backfill is important in avoiding mine collapse during and after extraction phases, ground subsidence in abandoned mines, and environmental damages. The stress distribution is one of the key factors in designing stope backfills. In this paper, we perform a numerical modeling study to investigate the stress distribution within and around the stope backfill. Importantly, our simulation results are in agreement with Marston's (1930) plain-strain arching theory. The results show that the stress arch is critical in stope backfills. The potential effects of internal friction angle, aspect ratio, and Poisson's ratio on stress distributions are also analyzed. The stress decreases when the aspect ratio, internal friction angle, and Poisson's ratio increase. Our results suggest that decreasing the aspect ratio and choosing materials with a high internal friction angle and Poisson's ratio are important for designing the stope backfill. The cohesive force index and elastic modulus also have significant effects on the stress distribution. Our findings have practical implications in designing stope backfills.
\end{abstract}

\section{Keywords}

stope backfill, Marston's theory, stress distribution, internal friction angle, cohesive force index, Poisson's ratio

1 College of Construction Engineering, Jilin University, Changchun, 130026, China

2 Engineering Research Center of Geothermal Resources Development Technology and Equipment,

Ministry of Education, Jilin University, Changchun, 130026, China

3 Earth and Environmental Sciences Division,

Los Alamos National Laboratory, New Mexico 87545

4 School of Earth Sciences, The Ohio State University,

Columbus, OH 43210, USA

5 Department of Geology,

University of Cincinnati, Cincinnati, OH 45221, USA

*Corresponding author, email: m.rezasoltanian@gmail.com

\section{Introduction}

Mining of minerals produces voids with different shapes such as stope, cave, room, and goaf. Several void refilling or backfilling methods have been developed in mining technology [1, 2]. Backfilling is essential for controlling regional geological stability, reducing possible collapse, and improving environmental safety [3-5]. Appropriate backfilling produces significant economic and social benefits by protecting surface buildings, mediating large underground void areas, and restoring mining safety.

A filling body is used in stope backfills to support the rock pressure, regulate the caving of the surrounding rock, and also to avoid mine collapse caused by large area goaf and the surface subsidence. The intention of stope backfill is to control the stress of the surrounding rock and also maximize its stability. The tailings, which add a certain amount of binder (e.g., cement), are usually used as backfill material [4]. Managing the added amount is important to ensure the stability of the backfill and also decreases the cost of backfilling. The difference in material properties (e.g., stiffness), between the backfill material and the surrounding rock, results in a stress re-distribution in the backfill and the rock. This induces arching effects. Arching, reduction in vertical stress within the yielding material, may occur during backfilling. This happens when a fraction of material yields while others stay in place. However, due to shear resistance along the interface of the yielding material and the stable zones, the yielding materials are retained in their original positions [6]. Note that arching effects occur in other structural systems such as silos and bins [7], ditches [8], and retaining walls [9].

Numerical simulation of the stress distribution within the backfill material and the surrounding rocks is the first essential step in backfill design [10]. In this paper, we develop a numerical model of a typical stope, and analyze the impact of geometrical and mechanical parameters on the stress distribution. The results help in understanding stress distribution and have implications in designing stope backfills.

Below we first review prior experimental, analytical, and numerical work related to backfill design. Importantly, Marston [11] derived a two-dimensional (2D) plain-strain theory 
of arching to estimate the stress distribution in stope backfills. We first use this theory to validate our numerical simulations. Terzaghi [12] and Terzaghi and Peck [13] extended Marston's theory by adding the cohesion effect. This enables the theory to be used for any material within the stope region (see also Aubertin et al. [14] for modified Marston's theory for cohesionless backfills). Winch [6] and Li and Aubertin [15] expanded the theory for estimating vertical stress in three-dimensional (3D) problems. Other analytical methods for analyzing arching theory are found in the literature (e.g., free standing vertical face by Grice [16], vertical slope by Grice [16], 3D sliding wedge failure by Mitchell et al. [18], and modified simple arching by Winch [6]).

Mitchel and Wong [18] studied backfill stability using twenty-six small-scale experiments and a 3D stress analysis method. They concluded that the arch effect had a significant influence on the backfill stability. Low et al. [19] studied arching effect of the pile in soft soils and clearly demonstrated that some stope stress was passed to the hard support body. Winch [6] and Li and Aubertin [15] investigated the Cannington mine filling to understand the stress arch in stope backfills using an experimental set up. They also analyze the influence of the filling material parameters. Take and Valsangkar [9] studied the horizontal stress distribution in a narrow stope backfill by a series of centrifugal experiments.

Numerical studies have shown that the stability of the stope increased with increasing cement content and declined in a typical mining height with increasing width [20-23]. Coulthard [24] developed a numerical model for stress distribution in cement slag backfill stope. Using FLAC3D, Pierce et al. [25] and Pierce [26] numerically analyzed the stability of a stope backfill and studied the potential effects of backfill materials. The arching effects in narrow stope backfills have been studied using FLAC and PHASES2 numerical simulators [14, 27-28]. Pirapakaran and Sivakugan [10] compared numerical models of arching effects in a stope backfill in narrow and circular stopes and compared their results with available analytical solutions. More field tests and numerical modeling results on stress distribution and arching effects are found in the literature [29-35].

The mechanical parameters strongly depend on the types and properties of materials. A number of studies on stope backfill have been conducted (cited work above). However, few have focused on model validations and analyzing the important effects of mechanical (internal friction angle, cohesive force, Poisson's ratio, and elastic modulus) parameters on stress distributions. In this paper, we analyze the effect of the mechanical parameters on the stress distributions of stope backfills.

This paper is organized as follow: Section 2 presents our numerical model and its comparison with Marston's theory. Section 3 presents sensitivity analyses to geometrical and mechanical parameters. Section 4 highlights the conclusions of this work.

\section{Numerical results and validation}

The conceptual model and the geometry of the stope backfill and the surrounding rock are shown in Fig. 1. Our numerical grid is shown in Fig. 2. We consider the stope dimensions of $\mathrm{H}$ $=45 \mathrm{~m}$ and $\mathrm{B}=6 \mathrm{~m}$ with a void space of $0.5 \mathrm{~m}$ from its top (see Fig. 1). The overall depth is $250 \mathrm{~m}$. The software FLAC was used to create our numerical model for the stope. The weight of the rock above the stope is simulated. After equilibrium of gravity, the stope is excavated and backfilled. The excavation and the backfill were modeled in 5 layers with thickness of $9 \mathrm{~m}$. The vertical stress, $\sigma_{v}$, in the rock mass is obtained by considering the overburden weight. The horizontal stress, $\sigma_{h}$, was assumed to be two times larger than $\sigma_{v}$, which is typical in the absence of any in-situ measurements. The rock mass is homogeneous, isotropic, and linearly elastic, with elastic modulus of $E=30$ $\mathrm{GPa}$, Poisson's ratio of $\mu=0.3$, and unit weight of $\Upsilon=2700 \mathrm{~kg} /$ $\mathrm{m}^{3}$. The granular backfill obeys a Mohr-Coulomb criterion. The backfill material properties are $E=300 \mathrm{MPa}, \mu=0.2, \gamma=1800$ $\mathrm{kg} / \mathrm{m}^{3}, \varphi=30^{\circ}$, and $c=0$.

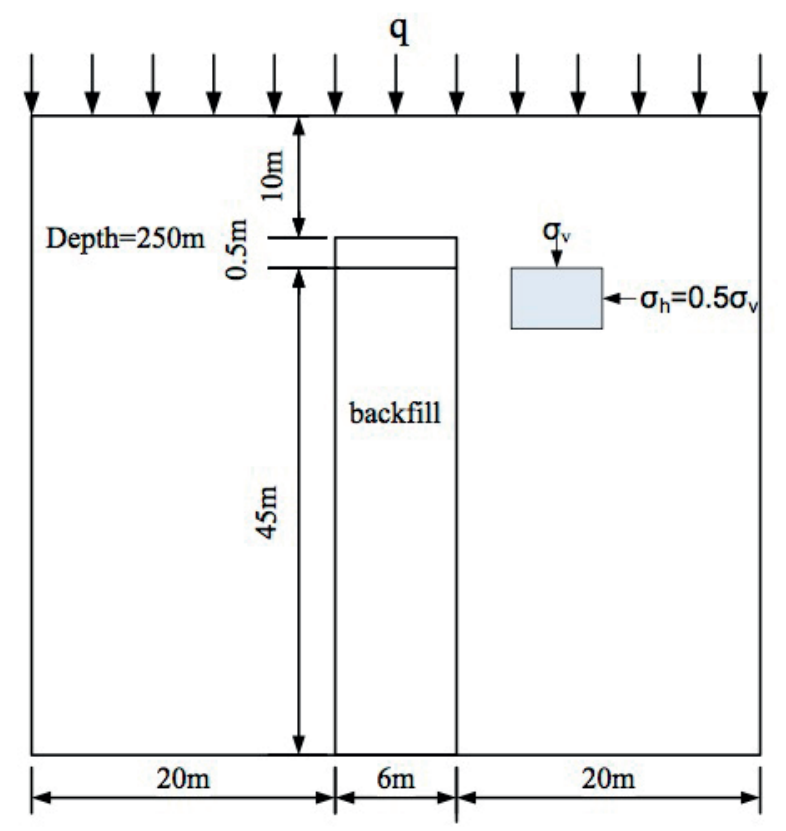

Fig. 1 Conceptual model for the vertical stope with backfill used in numerical models

Fig. 3 shows the vertical stress distribution within the stope and the surrounding rock. Our results showing a non-uniform stress distribution across the stope width are similar to $\mathrm{Li}$ and Aubertin [15] and Pirapakaran and Sivakugan [10]. Fig. 4 presents the vertical stress along the stope central line. The overburden pressure increases more rapidly than stress along the central line. This confirms that arching does take place in the stope backfill. The stress arch formation is clear in Fig. 3. As shown in Figs. 3 and 4 the arching effects become more important at higher depth and the vertical stresses is smaller than those due to the overburden pressure (weight of the backfill). Therefore, designers should consider special attention to the arch effect since it is a strength improving effect. 


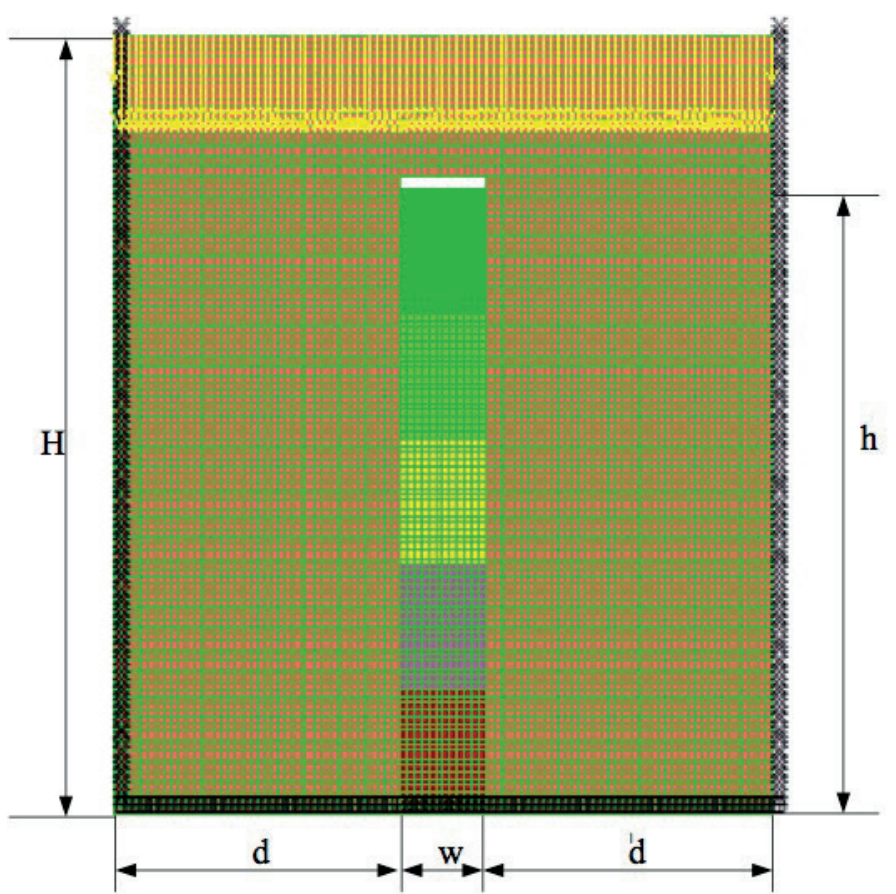

Fig. 2 Numerical grid for the vertical stope with backfill

Numerical models are usually employed to solve more complex problems that cannot be solved analytically. However, to increase our confidence for the numerical simulations results presented in next sections we validated our model using the plane-strain of arching by Marston's [11]. We confirm that there are several approximations and simplifications in Marston's [11] theory and its extensions. Marston presented a 2D plan-strain theory for arch stress. He developed the following models for $\sigma_{\mathrm{v}}$ and $\sigma_{\mathrm{h}}$ within the cohesionless mine fill stope:

$$
\begin{gathered}
\sigma_{v}=\frac{\gamma w}{2 \mu K_{a}}\left[1-\exp \left(-\frac{2 K_{a} \mu h}{w}\right)\right] \\
\sigma_{h}=\sigma_{v} K_{a}
\end{gathered}
$$

where,

$$
K_{a}=\tan ^{2}\left(45^{\circ}-\varphi / 2\right)
$$

where $\varphi$ is the internal friction angle, $\delta$ is the friction angle between the backfill material and the rock mass (typically it is between $\varphi / 3$ to $\varphi / 2$ ), $\mu$ is the friction coefficient between rock (it is equal to $\tan \delta$ ), and $K_{a}$ is the active earth pressure coefficient.

Fig. 4 compares our numerical simulation results for vertical stress along the stope central line to Marston's theory. It is clear that our simulation results are in agreement with those from Marston's theory. Also, the vertical stresses are less than the overburden pressure in both methods. Note that the vertical stress exceeding overburden pressure is not realistic and it could be in part related to model construction and the number of backfill layers. For instance, Aubertin et al. [14] and Li et al. [27] assumed that the backfill is placed instantly as one layer. Importantly, Li et al. [27] found that the Marston's theory underestimates the stress distribution. This conclusion is due to using a single layer backfilling. Placing the backfill in a number of layers gives a better prediction (see also Pirapakaran and Sivakugan [10]). Our simulation results were not sensitive to number of layers higher than five.

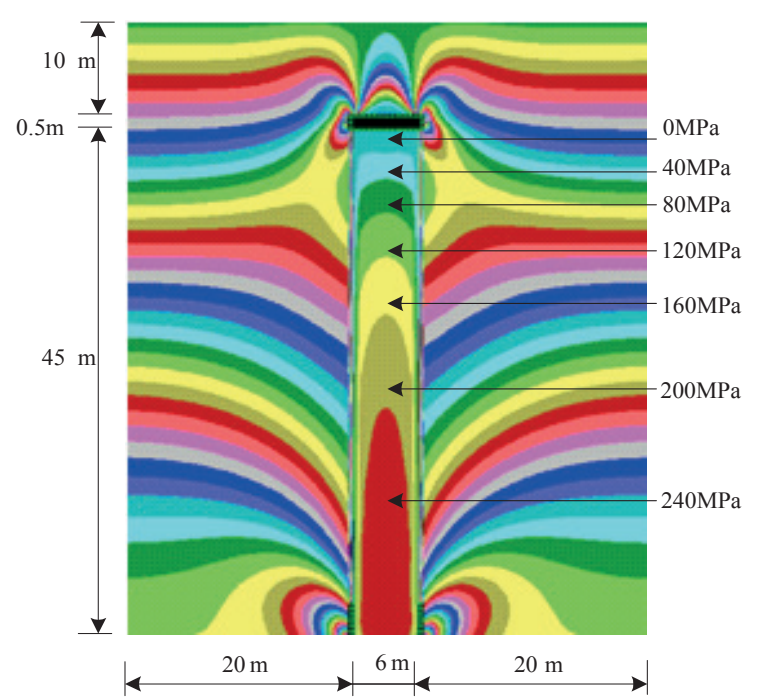

Fig. 3 Vertical stress distributions contours within backfill and surrounding rocks from numerical simulations

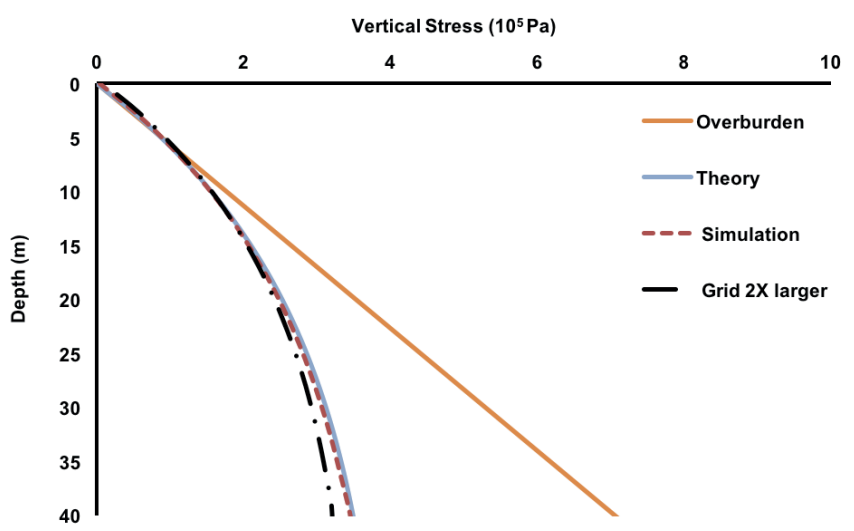

Fig. 4 Comparison of the vertical stress along the stope central line. Note that $w=6 \mathrm{~m}, h=45 \mathrm{~m}, \gamma=18 \mathrm{kN} / \mathrm{m}^{3}, c=0, \varphi=30^{\circ}, \delta=2 / 3 \varphi$

\section{Sensitivity analyses}

In this section, we present our simulation results to better understand the potential effects of geometrical and mechanical parameter on the vertical stress distribution. Note that we tested sensitivity of our simulation results to the grid size. As shown in Fig. 4, as we increase the grid size the vertical stress is under-represented.

\subsection{Effect of stope geometry}

The parameters defining the geometry of the stope backfill are the width $(\mathrm{W})$, the height $(\mathrm{H})$, and incline angle $(\alpha)$. Our sensitivity analyses show that the aspect ratio $(\mathrm{W} / \mathrm{H})$ of the stope backfill has a significant effect on the stress distribution. We chose aspect ratios of $0.15,0.2,0.3$, and 0.4 to analyze its effect on stress distribution. Fig. 5 shows the vertical stress from our simulations and overburden stress along the vertical centreline of the stope. The vertical stress is similar or close to 
the overburden in small depth for all aspect ratios. However, as the depth increases the vertical stress changes differently for each case. The higher the aspect ratio of stope backfill, the greater the vertical stress. Also, for small values of aspect ratio (0.15 and 0.2) the stress increases gradually with depth and reach to a constant close to the depth of $40 \mathrm{~m}$. When the aspect ratio is high, the stress increases rapidly with depth with an increasing trend, similar to the overburden pressure. Therefore, from the practical point of view, the aspect ratio of the stope should be considered as an important factor. In order to make sure that the vertical stress does not exceed the overburden pressure the smaller aspect ratio is more appropriate. However, with high values of aspect ratio, the stress in stope backfill might be passed to the surrounding rock.

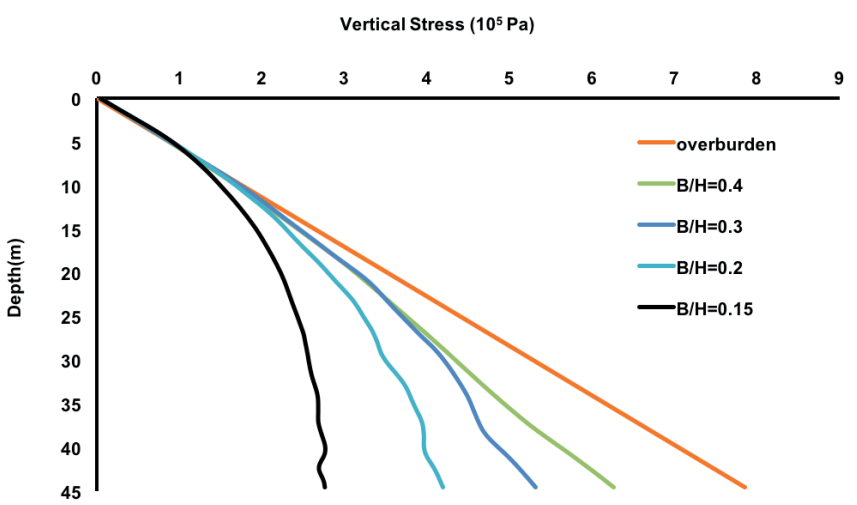

Fig. 5 Sensitivity to aspect ratio $(\mathrm{W} / \mathrm{H})$ of the stope backfill. Vertical stress is shown against depth along the central line

\subsection{Effect of mechanical parameters}

\subsubsection{Internal friction angle $(\varphi)$}

The internal friction angle $(\varphi)$ is one of the important parameters of the rock material. It is the index of shear strength, and represents the friction feature of the rock material. Here we used internal friction angles of $10,20,30$, and $40^{\circ}$ to analyze its effect on the stress distribution. The results are shown in Fig. 6.

As shown in Fig. 6, the vertical stresses are approximately the same for all angles for the upper third of the stope. Near the stope floor region, the vertical stress with $\varphi$ of $10^{\circ}$ is $\sim 55.6 \%$ of the overburden pressure. The vertical stress with $\varphi$ of $40^{\circ}$ is $\sim 68.9 \%$ of the overburden pressure. Increasing $\varphi$ from 10 to $20^{\circ}$ and 20 to $30^{\circ}$ results in $\sim 9.5 \%$ and $\sim 1.3 \%$ decrease in the vertical stress, respectively. The stress arch plays an important role when the internal friction angle of the backfill material is greater than $20^{\circ}$.

\subsubsection{Cohesive force (c)}

Since the backfill material contains adhesive and other additive materials, its strength is affected by cohesive force. We set the cohesive force index to $0,0.2,0.4$, and $0.6 \mathrm{MPa}$ to analyze its effects on the vertical stress. The results are shown in Fig. 7. As per Fig. 7 the cohesive force index does not significantly affect our results. The vertical stress decreases when the cohesive force increases. Increasing c from $0.1 \mathrm{Mpa}$ to 0.3 Mpa decreases the vertical stress more quickly than $\mathrm{c}$ from $0.3 \mathrm{Mpa}$ to $0.5 \mathrm{Mpa}$ does.

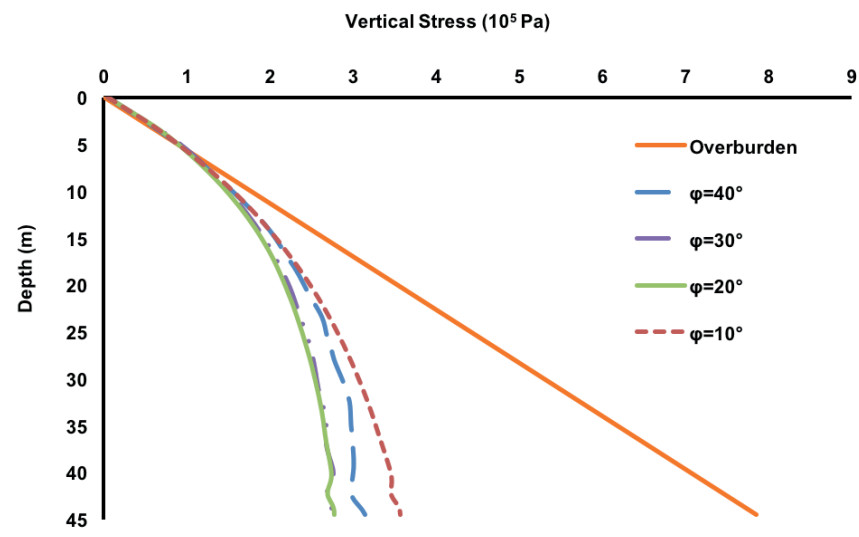

Fig. 6 Sensitivity to friction angle $(\varphi)$. Vertical stress is shown against depth along the central line

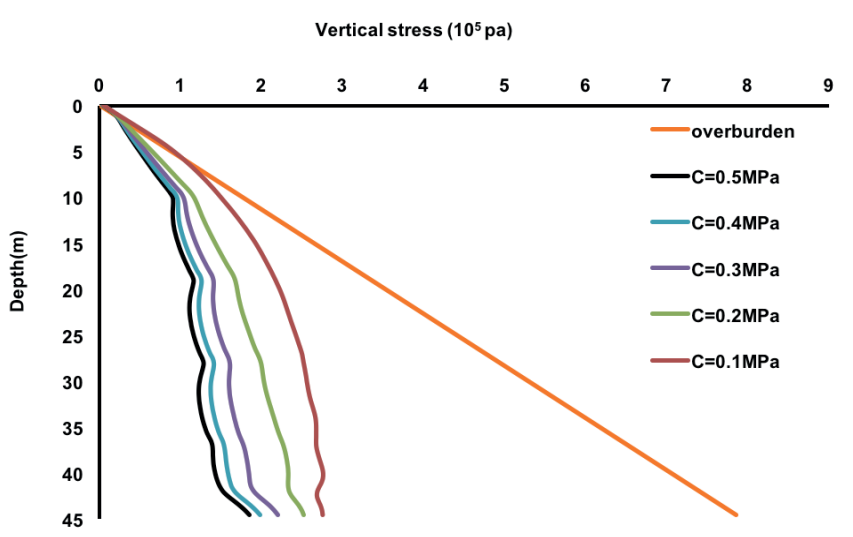

Fig. 7 Sensitivity to cohesive force index $(c)$. Vertical stress is shown against depth along the central line

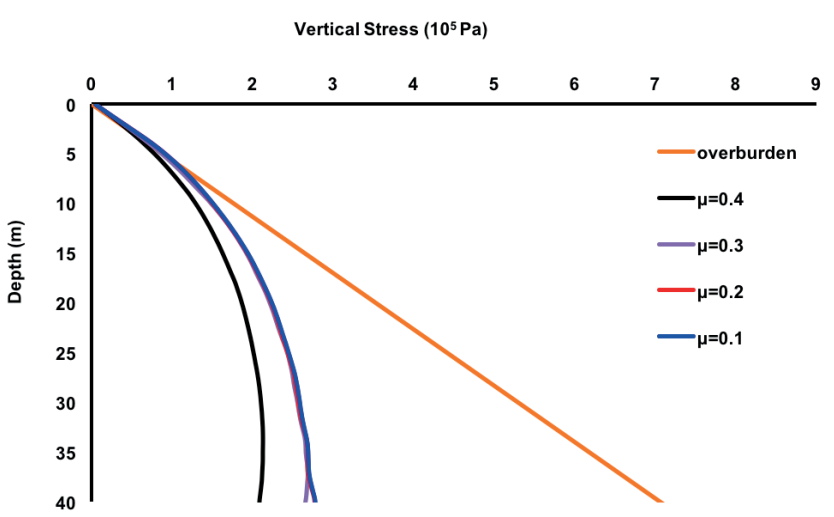

Fig. 8 Sensitivity to Poisson's ratio $(\mu)$. Vertical stress is shown against depth along the central line

\subsubsection{Poisson's ratio $(\mu)$}

Poisson's ratio is an important parameter that affects the properties of geotechnical materials. It is the ratio of the lateral and axial strains, reflecting the ability of the lateral deformation of the geotechnical material. We set the Poisson's ratio to $0.1,0.2,0.3$, and 0.4 to analyze its effect on the vertical stress. The results are presented in Fig. 8. The vertical stress along 
the central line of the stope is less than the overburden pressure. When Poisson's ratio increases from 0.3 to 0.4 , the vertical stress decreases. However, changing the Poisson's ratio from 0.1 to 0.3 did not significantly affect the vertical stress.

\subsubsection{Elastic modulus (E)}

Elastic modulus $(E)$ represents the resistance capability of the elastic deformation and can reflect the bonding strength between the particles. To analyze the effect of the elastic modulus on the vertical stress, we chose five different elastic modulus with values of 200, 250, 300, 350, 400, and $1500 \mathrm{MPa}$. We found that changing elastic modulus does not affect the vertical stress. Therefore, from practical standpoint, in designing the backfill materials, the effects of elastic modulus could be neglected.

\section{Conclusions}

Shortage of economic minerals in shallow subsurface has resulted in deep underground mining. Backfilling of mine waste is important for safety and environmental protection. It also avoids mine collapse and ground subsidence. We develop a numerical model to investigate the stress distribution within and around the stope backfill. We validated our numerical results with Marston's [11] arching theory that estimates the average vertical stress at any depth within the backfill. Using the validated model, we investigated the potential effects of geometrical and mechanical parameters on stress distribution. Important conclusions of this work are as follows:

1. Decreasing the aspect ratio of the stope backfill results in decrease in the vertical stress,

2. Vertical stress decreases when the aspect ratio, internal friction angle, and Poisson's ratio increase,

3. Cohesive force index and elastic modulus also have significant effects on the stress distribution.

4. Elastic modulus does not have a significant effect on the stress distribution.

These conclusions are significant from practical point of view and they help in better designing stope backfills.

\section{Acknowledgements}

This work has been funded by Engineering Research Center of Geothermal Resources Development Technology and Equipment in Ministry of Education at Jilin University. The third author thanks Jilin University for the start-up funding supporting this work.

\section{References}

[1] Smuda, J., Dold, B., Friese, K., Morgenstern, P., Glaesser, W. "Mineralogical and geochemical study of element mobility at the sulfide-rich Excelsior waste rock dump from the polymetallic $\mathrm{Zn}-\mathrm{Pb}-(\mathrm{Ag}-\mathrm{Bi}-\mathrm{Cu})$ deposit, Cerro de Pasco, Peru", Journal of Geochemical Exploration, 92(2-3), pp. 97-110, 2007. https://doi.org/10.1016/j.gexplo.2006.08.001
[2] Sheshpari, M. "A review of underground mine backfilling methods with emphasis on cemented paste backfill". Electronic Journal of Geotechnical Engineering, 20, pp. 5183-5208, 2015.

[3] Jiránková, E. "Utilisation of surface subsidence measurements in assessing failures of rigid strata overlying extracted coal seams". International Journal of Rock Mechanics and Mining Sciences, 53, pp. 111-119, 2012. https://doi.org/10.1016/j.ijrmms.2012.05.007

[4] Yao, Y., Cui, Z., Wu, R. "Development and challenges on mining backfill technology". Journal of Materials Science Research, 1(4), 73, 2012. https://doi.org/10.5539/jmsr.v1n4p73

[5] Wang, Y.M., Huang, M.Q., Wu, A.X., Yao, G.H., Hu, K.J. "Rock backfill and hazard control of abandoned stopes: A case study". In: Applied Mechanics and Materials, Trans Tech Publications, 368, pp. 1726-1731, 2013. https://doi.org/10.4028/www.scientific.net/AMM.368-370.1726

[6] Winch, C. "Geotechnical characteristics and stability of paste backfill at BHP Cannington mine". BE Hons Thesis, James Cook University, Townsville, Australia, 1999.

[7] Blight, G.E. "Pressures exerted by materials stored in silos: part I, coarse materials". Géotechnique, 36(1), pp. 33-46, 1986. https://doi.org/10.1680/ geot.1986.36.1.33

[8] Spangler, M. G., Handy, R. L. "Soil Engineering". Harper \& Row, 1984.

[9] Take, W. A., Valsangkar, A. J. "Earth pressures on unyielding retaining walls of narrow backfill width". Canadian Geotechnical Journal, 38(6), pp. 1220-1230, 2001. https://doi.org/10.1139/t01-063

[10] Pirapakaran, K., Sivakugan, N. "Arching within hydraulic fill stopes". Geotechnical and Geological Engineering, 25(1), pp. 25-35, 2007. https:// doi.org/10.1007/s10706-006-0003-6

[11] Marston, A. "The theory of external loads on closed conduits in the light of the latest experiments". In: Highway Research Board Proceedings, Bulletin 96, Iowa Engineering Experiment Station, Ames, Ia., Iowa State College, 1930.

[12] Terzaghi, K. "Theoretical soil mechanics". Wiley, New York, 1943. https://doi.org/10.1002/9780470172766

[13] Terzaghi, K., Peck, R. B. "Soil mechanics in engineering practice". 2nd Edition, John Wiley \& Sons, 1967.

[14] Aubertin, M., Li, L., Arnoldi, S., Belem, T., Bussière, B., Benzaazoua, M., Simon, R. "Interaction between backfill and rock mass in narrow stopes". Soil and rock America, 1, pp. 1157-1164, 2003.

[15] Li, L., Aubertin, M. "An analytical solution for the nonlinear distribution of effective and total stresses in vertical backfilled stopes". Geomechanics and Geoengineering: An International Journal, 5(4), 237-245, 2010. https://doi.org/10.1080/17486025.2010.497871

[16] Grice, A. G. "Recent minefill developments in Australia". In: Minefill 2001: 7th International Symposium on Mining with Backfill, pp. 351-357, 2001.

[17] Mitchell, R. J., Olsen, R. S., Smith, J. D. "Model studies on cemented tailings used in mine backfill". Canadian Geotechnical Journal, 19(1), pp. 14-28,1982. https://doi.org/10.1139/t82-002

[18] Mitchell, R. J., Wong, B. C. "Behaviour of cemented tailings sands". Canadian Geotechnical Journal, 19(3), pp. 289-295, 1982. https://doi. org/10.1139/t82-035

[19] Low, B. K., Tang, S. K., Choa, V. "Arching in piled embankments". Journal of Geotechnical Engineering, 120(11), pp. 1917-1938, 1994. https:// doi.org/10.1061/(ASCE)0733-9410(1994)120:11(1917)

[20] Bloss, M. L. "Prediction of cemented rock fill stability: design procedures and modelling techniques". University of Queensland, 1992.

[21] Bloss, M. L., Chen, J. "Drainage research at Mount Isa Mines Limited 1992-1997". In: Proceedings of 6th International Symposium on Mining with Backfill: Minefill, 98, pp. 111-116, 1998.

[22] Bloss, M. L., Revell, M. B. "Mining with paste fill at BHP Cannington". In: Minefill 2001: 7thInternational Symposium on Mining with Backfill, pp. 209-221, 2001. 
[23] Jewell, R. J., Fourie, A. B. "Paste and thickened tailings: A guide". Australian Centre for Geomechanics, The University of Western Australia, 2006.

[24] Coulthard, M. A. "Applications of numerical modelling in underground mining and construction". Geotechnical and Geological Engineering, 17(3), pp. 373-385, 1999. https://doi.org/10.1023/A:1008951216602

[25] Pierce, M. E., Bawden, W. F., Paynter, J. T. "Laboratory testing and stability analysis of paste backfill at the Golden Giant Mine". In: Minefill 1998: Proceedings of the 6th International Symposium on Mining with Backfil, Brisbane, Australia, pp. 14-16, 1998.

[26] Pierce, M. E. "Stability analysis of paste back fill exposes at Brunswick mine". In: Proceedings of the 2nd international FLAC symposium Lyon, France, pp. 147-156, 2001.

[27] Li, L., Aubertin, M., Simon, R., Bussière, B., Belem, T. "Modeling arching effects in narrow backfilled stopes with FLAC". In: Proceedings of the 3rd international symposium on FLAC \& FLAC3D numerical modelling in Geomechanics, Ontario, Canada, pp. 211-219, 2003.

[28] Li, L., Aubertin, M., Belem, T. "Formulation of a three dimensional analytical solution to evaluate stresses in backfilled vertical narrow openings". Canadian Geotechnical Journal, 42(6), pp. 1705-1717, 2005. https://doi.org/10.1139/t05-084

[29] Berry, P. "Geomechanical investigations for the design of cemented fill". In: Symposium on the Application of Rock Mechanics to Cut and Fill Mining, Luleå, Sweden, 1980; 190-192.
[30] Thomas, E. G., Holtham, P. N. "The basics of preparation of deslimed mill tailing hydraulic fill". Innovations in Mining Backfill Technology. (Hassani, F. F. (Ed.)). Rotterdam, Balkerna, pp. 425--431,1989.

[31] Rankine, K. J., Sivakugan, N., Cowling, R. "Emplaced geotechnical characteristics of hydraulic fills in a number of Australian mines". Geotechnical and Geological Engineering, 24(1), pp. 1-14, 2006. https://doi. org/10.1007/s10706-004-1511-x

[32] Rankine, K. J. "An investigation into the drainage characteristics and behaviour of hydraulically placed mine backfill and permeable minefill barricades". James Cook University, 2005.

[33] Sivakugan, N., Rankine, K.J., Rankine, K. S. "Study of drainage through hydraulic fill stopes using method of fragments". Geotechnical and Geological Engineering, 24(1), pp.79-89, 2006. https://doi.org/10.1007/ s10706-004-1949-x

[34] Sivakugan, N., Rankine, R. M., Rankine, K. J., Rankine, K. S. "Geotechnical considerations in mine backfilling in Australia". Journal of Cleaner Production, 14(12), pp. 1168-1175. 2006. https://doi.org/10.1016/ j.jclepro.2004.06.007

[35] Helinski, M., Fahey, M., Fourie, A. "Numerical modeling of cemented mine backfill deposition". Journal of Geotechnical and Geoenvironmental engineering, 133(10), pp. 1308-1319, 2007. https://doi.org/10.1061/ (ASCE)1090-0241(2007)133:10(1308) 